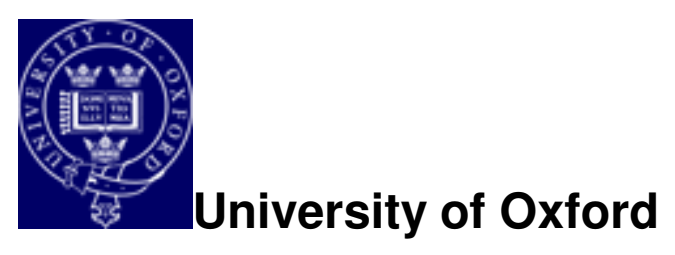

Department of International Development

SLPTMD Working Paper Series

No. 001

\title{
Economic Development From the Perspective of Evolutionary Economic Theory
}

Richard R. Nelson 
Economic Development From the Perspective of Evolutionary Economic Theory ${ }^{1}$

\author{
Richard R. Nelson \\ Columbia University
}

\begin{abstract}
:
Sanjaya Lall saw economic development as an evolutionary process, with technological learning at its heart. This essay lays out the key differences between an evolutionary theory of economic activity and change, and the neoclassical theory as articulated in economic text books. It argues that only an evolutionary theory fits what is known about how technological learning progresses. It also argues for recognition, right at the basis of economic theorizing, that modern economic systems contain a rich mix of institutions, and not simply the firms, households, and markets, that are in neoclassical theory, and that the roles of government cannot be adequately understood as simply responses to "market failures". It develops a view that long run economic change must be understood as involving the co-evolution of technologies in use and the institutional structures supporting and regulating these.
\end{abstract}

\footnotetext{
${ }^{1}$ This essay draws heavily from the keynote address I presented at the October 2004 meeting of Globelics, held in Beijing China
} 


\section{ECONOMIC DEVELOPMENT FROM THE PERSPECTIVE OF EVOLUTIONARY ECONOMIC THEORY}

Sanjaya Lall believed that economic development had to be understood as an evolutionary process, with technological learning at it's core, and that standard neoclassical economics was completely inadequate as a theory of what was going on (see e.g. Lall in Kim and Nelson, 2000). In my essay in this volume honoring him, it seems appropriate that I lay out the basic differences between evolutionary economic theory, at least my style (which I think also was Sanjaya's), and neoclassical theory. I then go on to argue that an adequate theory needs to recognize the rich mix of institutions that are involved in economic activity - not just firms, households, and markets - and also that the varied roles of government cannot be understood simply as responses to "market failures". I then will develop the argument that long run economic change involves the co-evolution of the technologies known and in use, and the institutions supporting and regulating these. While I cannot be sure, I think Sanjaya would have agreed.

\section{The Basic Differences ${ }^{2}$}

At the broadest level, and possibly the deepest, the difference between the evolutionary economic theory that is taking shape, and the neoclassical theory that has dominated microeconomic theorizing over the last half century, is that evolutionary theory sees the economy

\footnotetext{
${ }^{2}$ I will not discuss here the differences in the styles of formal modeling in the two theories, save to note that formal modeling in evolutionary theory tends to take the form of dynamic systems that at any moment may be far from an equilibrium, while formal neoclassical models almost always assume that an equilibrium obtains. My focus here is not on formal modeling, but on what Sidney Winter and I (1982) have called "appreciative theory", that is theory that aims to capture the basics of what actually is going on.
} 
as always in the process of change, with economic activity almost always proceeding in a context that is not completely familiar to the actors, or perfectly understood by them. In contrast, neoclassical theory sees the economy as at rest, or undergoing well anticipated change, in any case with actions appropriate to the context something the decision makers have learned through relevant experience, or can calculate accurately based on what they know securely. In turn, this difference in the way the economic scene is interpreted leads to important differences in the operational parts of the theories.

One basic consequence of the difference between the two theories in how the economic context for action is viewed, is that they put forth very different views on what is meant by "rational" behavior. Both theories assume that individual and organizational economic actors pursue objectives, usually in a reasonably intelligent way. However, the "rationality" of actors in evolutionary theory is bounded, in the sense of Herbert Simon (1955). There is no way they can understand fully the context in which they are operating, yet they have to cope, somehow. To a considerable extent the coping involves the use of routines that have in the past yielded satisfactory results. But the actors in evolutionary theory also have the capability to do something new, to innovate, if they think they see an opportunity, or when what they have been doing becomes clearly inadequate in a changed context.

This is a very different view of economic behavior than one that presumes that the actors face given and fully understood choice sets, and make optimal choices given those sets. The latter may make sense if one could assume that the economic context is basically unchanging, that economic actors have had sufficient experience to learn what works and what doesn't in that context, and that there has been sufficient time for selection to winnow out or force 
transformation of incompetent behavior. But if the economic context tends to be in flux, with change coming both from changes in external conditions, and from developments internal to the operation of the system, such a presumption is misleading. It blinds analysis to the fact that economic actors in many cases may operate in ways that have sufficed in the past, but which may be far from the best that can be done given current conditions. It misses the uncertain groping that almost always characterizes individual and organizational action taking in contexts that are poorly understood, and the fact that individual and organizational actors often can and do behave in innovative ways.

A related difference between the two theories is in how they conceive good economic performance. Neoclassical theory proposes that the performance of an economy should judged in terms of how close it is to a theoretical optimum. In evolutionary theory there is no theoretical optimum, since the range of possibilities for economic action is always changing, generally growing, but in a way that cannot be predicted or specified in detail. Economic performance is seen in terms of the rate and nature of progress. Sanjaya Lall argued that economic progress needed to be understood as a learning process. That is exactly the perspective of evolutionary economic theory.

The focus of modern evolutionary economic theory on economic progress scarcely is a radical new departure. Indeed Adam Smith, in The Wealth of Nations, was basically concerned with illuminating the processes of economic development, and the institutions supporting the key processes. Much of his comparative analysis was concerned with identifying the reasons why some countries seemed to have been making significant progress, while others seemed stagnant. This orientation towards economic progress, the factors stimulating progress, and those limiting it, remained central in economic analysis, until the development of neoclassical theory pulled the 
focus more sharply towards the properties of a hypothetical economic equilibrium.

I also want to note, or rather to highlight, that most of the useful understandings that are contained in modern economics are not tied to modern neoclassical theory, with its focus on conditions of hypothetical equilibrium. Propositions like "demand is responsive to price", "competition tends to keep prices in line with costs", "an economy in which markets play a significant role has a capacity for self-organization and adaptation to changes in basic economic conditions", and "attempts to give detailed direction to an economy from the center tend to be incompetent or worse", are not dependent on "theorems" derived from modern neoclassical economic theory. You will find all of the above in Adam Smith, over 200 years ago..

Of course modern evolutionary theory has been strongly influenced by Schumpeter. It is interesting, and relevant, that in his Theory of Economic Development, Schumpeter (1934) used the concept of a circular flow equilibrium, where habitual, customary, behavior sufficed, indeed was hazardous to abandon, as the vehicle to contrast with what is involved in economic development, where innovation was driving change, and the system was out of equilibrium. Schumpeter's conception of behavior in the circular flow was his interpretation of Walrasian general equilibrium, and an interesting way of characterizing the conditions under which modern neoclassical economics would be a good characterization of what was going on, particularly if maximizing behavior is interpreted, as it was by Milton Friedman (1953), as a way of "predicting" and describing behavior that has been winnowed by learning and competition. I note that modern economic evolutionary theory becomes very similar to neoclassical theory, and generates a continuing equilibrium "circular flow" of economic activity, when innovation is shut down for an extended period of time. But Schumpeter's basic point was that, if innovation is an important part of what is going on, this characterization of economic activity is inappropriate. 
I would like to highlight a particular aspect of Schumpeter's treatment of innovation in his $\underline{\text { Theory of Economic Development }}$, that he carries over into his later Capitalism, Socialism, and Democracy (1950), because it is a central element of evolutionary theory. It is the presence of uncertainty.

I note here that Schumpeter's concept of uncertainty is close to that of Frank Knight (1921); absence of sufficient relevant experience for the actor to estimate relevant probabilities reliably, or even to list in any detail the states of affairs that might materialize after an action is taken. The essence of trying something new, of innovation, is that what will happen is uncertain in this sense, with success never a sure thing. And where and when a considerable amount of innovation is going on, being done by different economic actors, the current context is particular uncertain. In such a context, considerable progress may be being made by the economy as a whole, but through a process of "creative destruction" that involves losers as well as winners. The evolutionary economic theory that Sidney Winter and I helped to develop, as an alternative to neoclassical theory, was strongly inspired by Schumpeter.

However, there is an important blind spot in Schumpeter, that I would like to flag here, that also was there to some degree in the early articulations of evolutionary economic theory. It is failure to recognize the institutional complexities of modern market economies. Of course the same problem is there in neoclassical economic theory. Indeed one explanation for the institutional oversimplification in Schumpeter and in early modern evolutionary theory is that, in focusing their attacks and proposals for reform on the limitations of the equilibrium concept, the writers failed to pay sufficient attention to the spare institutional assumptions of that theory. That theory contains firms, who employ inputs to produce outputs. There are households who supply primary inputs and who purchase final outputs. And there are markets that somehow work, 
through the adjusting of prices, to equilibrate supply and demand. That's it!

The innovation systems strand of research is designed to enrich this overly spare institutional picture. It does so in two somewhat distinct, but overlapping ways. One is to recognize the complexity of many market relationships, their embedding in broader social and institutional structures, and the elements of cooperation and trust that often are essential if markets are to work well. The other is to highlight the role of non-market institutions, like university and public research systems, scientific and technical societies, government programs, in the innovation process in many sectors. While there has been a tendency in the innovation systems literature to focus on institutions involved in the early stages of the innovation process, particularly $\mathrm{R}$ and $\mathrm{D}$, some treatments also include in the innovation system the labor market, the education system, financial institutions, regulatory structures, and other institutions that shape economic dynamics more broadly.

Particularly the latter strand makes the research on innovation systems very much part of the recent broad movement in economics to develop a new institutional economics. While sometimes not recognized for what it is, this is a major step away from the Walrasian model. However, I think it fair to say that there are significant differences between the adherents to a richer institutional view who, in other regards, try to hold on to the basic tenets of neoclassical theory, and those coming from evolutionary economics, who thus far mostly have been associated with the innovation systems writings.

One important difference is that, in the neoclassical writings, the normative justification for structures that regulate markets and for non-market structures more generally is posed in terms of "market failures". The evolutionary theoretic view on this, or at least my view, is that this mode of normative analysis involves a major asymmetry and often obfuscates understanding. 
Once one recognizes the wide range of institutions involved in economic activity, and acknowledges as well that no particular institution ever works "perfectly" in any real context, the asymmetry involved in justifying non-market modes simply in terms of the inadequacy of markets stands out. It becomes apparent that normative analysis needs to be oriented to comparing imperfect alternative modes of organization and governance, and possible mixes of them.

Thus public funding of basic research, conducted largely at public labs and universities, is a reasonable policy not so much because of "market failure", but because well allocated basic research spending yields high expected social returns, and publicly funded research conducted at public institutions would appear to be the best way of getting certain kinds of research done and the results made available for general use. Similarly, it makes much better sense to argue for well designed industrial policies in terms of high expected payoffs (if in fact that can be argued) than to go through a litany of "market failures" that might justify such policies.

Another important difference between a neoclassical and an evolutionary perspective on institutions and institutional change goes back to the basic differences in the theories I discussed above. Neoclassical economists tend to see institutions as created through and operating as they do because of the maximizing behavior of economic agents, and prevailing institutions as an equilibrium configuration. In contrast, evolutionary economists tend to see the institutional structure as always evolving.

\section{Evolutionary Economic Theory as Growth Theory}

The empirical research during the 1950s and 1960s on the sources of macroeconomic growth firmly established that technological advance was the key driving force. These findings 
led to a surge of research by economists on the processes of technological advance, and to the rediscovery of the features of economic activity where innovation was important that had been argued years before by Schumpeter. It continues to puzzle and sadden me that so many of my colleagues in economics interested in economic growth continue to hold onto a neoclassical growth theory that cannot deal adequately with an economic context in which innovation is important.

The evolutionary growth models that I and my colleagues developed in the 1980s were, I think, a significant step towards the development of a viable theoretical alternative. However, as I mentioned above, those early evolutionary analyses lacked a way of seeing onto the complex institutional structures that characterize modern economies.

I think that, as a result of the bringing of institutions under the umbrella of evolutionary theory, evolutionary economics now has the capability to provide a broad, coherent, and useful theory of economic growth as experienced in the advanced industrial economies. . A satisfactory growth theory of course has to be able to make sense out of the aggregate time series of output, measured by real GNP, and aggregate inputs like labor and physical and human capital. The early evolutionary growth models showed that a growth theory based on evolutionary economics could do this as well as a growth theory based on neoclassical economics.

But I would argue that a satisfactory growth theory has to do a lot more than just that. A satisfactory growth theory should be able to illuminate the important details of growth, qualitative as well as quantitative, that one sees in the accounts of economic historians. And a satisfactory theory needs to specify correctly the basic processes driving economic growth. Otherwise that theory does not explain what actually is happening.

The new evolutionary growth theory that is emerging sees economic growth as the result 
of the coevolution of technologies, firm and industry structures, and supporting and governing institutions. I propose that a satisfactory theory of the processes involved in economic growth must consider all three of these aspects, and that the driving dynamics involves their interaction. To illustrate, it is useful to consider several empirical cases.

Let me begin with the rise of mass production, in the United States. As Alfred Chandler $(1962,1977)$ tells the story, the development towards the middle of the $19^{\text {th }}$ century of telegraph and railroad technology opened the possibility of business firms to market their products over a much larger geographical area, and along with the advances that were being made at the same time in the ability to design and build large scale machinery, opened up the possibilities for significant economies of scale and scope. However, to exploit these opportunities, firms had to be much larger than had been the norm, and large size posed significant problems of both organization and management. The organizational problem was solved by the emergence of the modern hierarchically organized company, and later by the multi divisional form of organization. But to manage these huge companies required many more high level managers than an owner could garner by canvassing family and friends, which had been the usual practice. The notion of professional management came into being, and shortly after Business Schools emerged as the institutional mechanism for training professional managers. The financial needs of the giant companies were beyond what could be met through existing financial institutions, and both modern investment banks and modern stock markets emerged to meet the needs.

All of these developments raised complicated issues of corporate, labor, and financial law. Gradually these were worked out. At the same time the market power of the new large firms, and their tendency to collude with each other, gave rise to new regulatory law and anti trust. Another interesting example is the rise of the organic chemical product industry in 
Germany, as told by Peter Murmann (2003). Here the initiating cause was a breakthrough in the science of organic chemistry. As a result, persons with advanced training in the theory and techniques of chemistry had a special capability for developing synthetic dyestuffs. In order to take advantage of this new capability, business firms had to develop the concept and structure of the industrial research laboratory, as a place where university trained scientists could work with their peers in discovering and developing new products. And the German university system had to gear itself up to train significant numbers of chemists inclined to work for industry. The various German governments provided significant funding to enable this latter development to happen.

My third case is a more contemporary one, the revolution in pharmaceuticals that has occurred over the last forty years, particularly in the United States. The development during the 1960s and 1970s of molecular biology as a strong science, and the creation of the basic processes used in modern biotechnology, clearly was a watershed. These developments opened up a new route to pharmaceuticals discovery and development, one in which, at least at the start, established pharmaceuticals companies had no particular competences, and at the same time, one where certain academic researchers had particular expertise. Several lines of university based research began to appear commercially very promising. A number of new biotech firms were formed, staffed by university researchers and their students, with plans to develop new pharmaceuticals, and either license the successful results, or themselves go further downstream into the pharmaceuticals business.

There were two institutional factors that enabled and encouraged these developments. One was the traditional openness of American universities to entrepreneurial activity on the part of their researchers. The other was an established venture capital industry, which quickly came 
to see the finance of biotech start-ups as a potentially profitable business.

In 1980 a key legal decision assured skeptics that the products of biotech could be patented. At the same time, Congress passed the Bayh-Dole act, which encouraged universities to take out patents on the results of their government funded research projects, and to try aggressively to commercialize those results. This latter development was accompanied by growing support of the National Institutes of Health for research at universities in the relevant fields, under the expectation that universities would actively engage in patenting of research results and efforts to spur commercialization. These developments strongly reinforced the developing structure that I have described above.

The pharmaceuticals industry has changed in many ways since the times I have just described. However, there would be widespread agreement that these developments set the stage for an era of high productivity of pharmaceuticals research, albeit with apparent diminishing returns in recent years, and for U. S. dominance in commercial biotech, which holds to the present time.

All three of the above accounts are of a piece of the economy, not the whole, although the developments Chandler described had very widespread impact. I firmly believe that economic growth cannot be understood as an undifferentiated aggregate phenomena, but rather one needs to understand an economy as consisting of many different sectors each with their own dynamic.

However, I also believe that there is a lot to Schumpeter's theory, presented in his Business Cycles (1939), that the history of economic growth tends to divide up into eras, and that within any particular era there is a relatively small set of technologies and industries that are driving economic growth. Schumpeter's theory clearly involves the coevolution of technology, and firm and industry structure. Recently Christopher Freeman and Carlotta Perez (1988) have 
proposed that the key technologies and industries of different eras generally require different sets of supporting institutions. Their argument is that the nations that tend to be leaders in the different eras are those that had, or managed to build, the appropriate set of institutions.

In the discussion above I have tried to highlight several things. First, once one pays attention to the details, one virtually is forced to take an evolutionary perspective on economic dynamics. A framework that assumes full rational decision making, and a context of continuing equilibrium, is of no use at all. Second, the stories presented above involve in an essential way the coevolution of technology, firm and industry structures, and a variety of non-market institutions. An account limited to the Walrasian actors would miss much of the important action. Third, public policies and programs, including the development of law, are an essential part of the dynamic.

Evolutionary Theory, and Economic Development.

I propose that these same features also are there in the rapid economic development of countries, originally far behind the frontier, who have broadly caught up. Successful development involves the coevolution of technologies employed, firm and industry structure, and broader economic institutions. Government policies and programs are an essential part of the picture, for better or for worse, but inevitably. I am sure that Sanjaya Lall would agree with all of the above.

For countries aiming to catch up, the basic challenge is to learn to master new ways of doing things. This involves breaking from the circular flow of economic activity that Schumpeter used as his base concept for defining what he meant by innovation. In Schumpeter's sense of the term, catch up requires innovation. The innovation involved in catch up is not what economists studying technological advance in countries at the frontier tend to mean by the term. The 
innovation in catching up involves bringing in and learning to master ways of doing things that may have been used for some time in the advanced economies of the world, even though they are new for the country or region catching up. In most cases there are models in advanced countries that can serve as targets for emulation, and in many cases active assistance is available in developing the new capability. In some cases important aspects of the model can be simply imported.

But bringing into operation practices that are new in the context involves an essential break from Schumpeter's circular flow of customary activity. The record is clear that there is considerable learning that needs to be done to enable the new modes of operation to be got under effective control, and a high chance of failure. These are the hallmarks of innovation, at least in evolutionary economic theory.

Neoclassical growth theory misses all of this. In a recent article Howard Pack and I (1999) argued that neoclassical theory sees economic development as largely driven by accumulation - investments in physical and human capital. In contrast, we argue that the key driving force of catch-up is assimilation, learning to do effectively what countries at the frontier have been doing, often for some time. We recognize, of course, that countries behind the frontier that have made successful progress in closing the gap have been marked by high rates of investment in physical and human capital. These were needed to bring in the new ways of doing things, but not sufficient. The premise of neoclassical theory is that, if the investments are made, the acquisition and mastery of new ways of doing things is relatively easy, even automatic. The experience of some of the Communist economies in the period between 1960 and 1990 shows how wrong is this presumption. High rates of investment, without effective assimilation, 
inevitably result in low returns to those investments, and little in the way of effective development.

In contrast, Pack and I argue that the driving force of successful catch-up is innovation, in the sense described above. Successful innovation requires access to physical and human capital. However, to a considerable extent, innovation and effective learning tend to draw supplies of physical and human capital by enabling their rates of return to be high. Of course, if a country does not have the institutional structure that enables physical and human capital to be drawn to, or created for, promising innovative efforts, innovation will be scotched. But as we read the successful histories of catch-up in Japan early in the twentieth century, and Korea and Taiwan toward the close of the twentieth century, it was innovation that was driving the process, proceeding in an environment where supplies of physical and human capital were available and forthcoming if the returns were high.

Much of the standard discussion about what is needed for catch-up focuses on the need for access to and achievement of mastery over modern technologies. I would like to propose that that job today is in some ways easier and in some ways more difficult than it was when Korea and Taiwan were successfully taking aboard modern technologies. It is easier because the body of relatively codified knowledge underlying most important technologies has become much stronger than was the case, say, thirty years ago, and much of that knowledge can be garnered through training, sometimes advanced training, in the relevant sciences and engineering disciplines. The need for technological apprenticeship in, or tutelage by, companies in the leading countries, therefore, has diminished. I am not arguing that a freshly MIT trained engineer, or a Ph.D. scientist, can step right in and be effective in the operation of a modern 
technology. However, that training provides a substantial base for learning by doing and using. From this point of view, technological catch-up is easier today than it was fifty years ago.

But from another point of view, it is harder. There is, first of all, greater need for large scale public and private investments to create a technologically sophisticated cadre of indigenous engineers and applied scientists. While in the early stages of catch-up much of the needed technical sophistication can be gained by sending students to study abroad, as development proceeds, and the sheer quantity of needed engineers and scientists increases, a large share of the education is going to have to be undertaken indigenously. I propose that in the current environment, catch up will be impossible unless a country builds up its education system, from bottom to top. This poses a major challenge both for financing, and for institution building.

In addition, in today's world, countries seeking to catch up technologically will be operating under a much more restrictive regulatory regime defined by international treaties than was the case earlier. TRIPs makes copying, or appearing to copy, much more hazardous in terms of generating lawsuits and diplomatic pressure than used to be the case. And at the same time, treaties enforced through the WTO significantly narrow the range of government policies of protection and subsidy that can be undertaken in support of infant industry. It is interesting, and I think highly relevant, that these treaties do leave room for support of training, and certain kinds of research and development. But to take advantage of this opening poses a major institutional challenge.

Successful catch-up involves much more than simply gaining mastery over new technologies, and building up a technologically sophisticated work force to work with them. Just as new wine seldom goes in old bottles, the new technologies taken aboard call for new ways of organizing and managing work, and the experience of earlier episodes of successful catch up 
indicates that to achieve this involves a painful process of creative destruction. As Japan took aboard more advanced technologies in the early years of the twentieth century, and Korea and Taiwan did in the later years, the economic structures of these countries were transformed. New firms were founded, and whole new industries. Old firms and industries disappeared. Once can see the same developments happening in China today.

Achieving the needed reforms in economic structure may well be a more difficult task than gaining the scientific and engineering knowledge needed to operate the new technologies. There are several reasons.

One is the political power of old firms and industries, and the difficulties they may have in transforming themselves. For comfortable, politically well connected, old firms, creative destruction is not a welcome thing. Politically and socially, creative destruction is not easy to handle.

Another reason is that the modes of organization and management in successful companies in advanced countries generally are more difficult to imitate, or to transfer, than the technologies that they are using. Unlike the situation regarding technologies where, I have argued, an increasing share of the relevant knowledge has become codified, successful large organizations remain very difficult to understand, much less to imitate. Various pieces of the modern management literature suggest strongly that managers of successful companies may have hazy, or even wrongheaded, notions as to why their own companies are doing well. And various studies have indicated strongly that effective organizational structures and management styles come into existence as least as much through internal evolutionary processes, as through conscious planning. 
It is interesting that while in recent years there have been a number of empirical studies of the processes through which countries, and firms in countries, that have been successful in catchup and have come to master modern technologies, there has been very little detailed study of the process of transformation of firm and industry structure. Clearly a number of different routes have been successfully taken. Korea self-consciously opted for an industry structure involving large, diversified firms. The Taiwanese industrial structure that has been successful in modernization has involved medium-size firms, and continuing new firm entry. Some countries like Korea have held off direct foreign investment. Others like Singapore have welcomed it. All of these countries, however, seem to have been effective in creating a firm and industry structure that could successfully organize and manage modern technologies. Other countries have been much less successful at this. It would be extremely interesting to learn more about the differences.

Of course the rate and effectiveness of the needed changes in firm and industry structure, as well as the vigor and effectiveness of efforts to adopt and master new technologies, depends on the institutional structures supporting and molding economic activity, and the extent to which they facilitate productive change. Despite the growing influence of the new institutional economics, much of the analysis of development done from a neoclassical perspective continues to see the needed supporting institutional structures as very simple, basically those that support efficient market organized economic activity as viewed through neoclassical theoretical glasses. Thus there is emphasis on a well drawn and well enforced code of commercial law, strong intellectual property rights, a distancing of government from market economic activity with policies aimed to let the market work, fiscal and monetary policies that support productive investment and avoid inflation, etc. There may be some talk about the role of government in 
providing needed infrastructure, particularly in the field of education, but I have seen no coherent discussion of this.

As the examples presented in the preceding section show, the institutional context within which economic growth proceeds in high income countries is much richer, and active, than the standard neoclassical picture. This certainly also seems to be the case also in the experiences of successful catch up.

As I indicated earlier, I am using the term innovation system to encompass the wide range of institutions that are involved in supporting and orienting the dynamics of economic activity where innovation is the key driving force. In my discussion above, I have identified a number of institutions that strike me as absolutely key to the catch-up process. The structure of the financial system obviously is pivotal. Since the catch-up process involves a significant shifting of resources away from old firms and industries, the financial system must enable this transfer. And in the present era, the education system is of vital importance. Over the last century, all the countries that have been successful in catching up have had a system of primary and secondary education that endowed a large fraction of the young population with the basic skills needed to operate in a modern technology, and also provided high level training for a sufficient cadre of scientists and engineers to enable foreign technologies to be absorbed.

The fact that today so much of technology is science based means, I believe, that a country's system of advanced training in science, technology, and the other bodies of knowledge needed to master modern ways of doing things, is going to be even more important in the $21^{\text {st }}$ century than it was in the $20^{\text {th }}$. And research at universities and public labs is going to play a more important role (for a discussion see Mazzoleni and Nelson, forthcoming). 
While overlooked in much of the writings on economic development, indigenous public sector research long has been an important element of catch-up in certain fields. This is certainly so in agriculture, and here agricultural economists have provided a considerable amount of analysis and evidence. It also would appear to be true regarding medicine, although I have not been able to find much in the way of systematic study here. An important part of the reason in both of these fields is that in these areas developing countries often could not simply copy technology and practice in countries at the frontier, but needed to develop technologies suited to their own conditions. Soil and climate conditions tend to be different. The prevalent diseases were different. There is every reason to believe that the importance of having a capability to do effective research and development in agriculture and medicine will be as important in the future as it has been in the past. In these areas, international institutions have played important roles in the past, and will continue to do so in the future. But I suspect strongly that there are major advantages to a country in building up its own research capabilities in these areas.

In contrast with agriculture and medicine, while in manufacturing the technologies used in advanced countries may not have been optimal, at least they worked in the new setting with often modest modification. And they were generally available. The experience of countries that have successfully caught up in manufacturing over the past half-century testifies to the importance of a nation's university system in providing a supply of trained engineers and applied scientists for manufacturing firms' catching up. However, while there are interesting exceptions (electronics in Taiwan, and aircraft in Brazil, are examples), it is not clear that in the past research per se in universities and national laboratories has played an important role in catch-up in manufacturing, beyond its role in the training function. 
I would like to argue that circumstances have changed. There is, first of all, the fact that many important technologies now have a strong science base. As I noted earlier, this at once presents a problem for developing countries, in that they cannot learn to master these technologies unless they have a highly trained work force, including a cadre of sophisticated scientists and engineers, but also provides an opportunity, in that a larger share of the needed knowledge is open to those who have the capacity to stay with it. In many of the relevant fields, an important part of the activity of staying up with developments in a technology involves an active research program. Universities and public laboratories are an appropriate place for this kind of research, if these institutions also provide training and experience for scientists and engineers who will go out into industry. Earlier I also noted both the new international regimes' stronger protection of intellectual property, and the apparent leeway under WTO rules for certain kinds of public research.

There is no question in my mind that for countries aiming to catch up, developing the capabilities for learning and innovation in firms is the heart of the challenge. However, a strong system of university and public labs research can play a very important supporting role.

\section{The Case for an Evolutionary Theory of Economic Catch-up}

I want to conclude this essay by reflecting briefly on the role of theory in economic analysis, and the case for an evolutionary economic theory. I propose that theory in economics exists at several different levels of abstraction. Sidney Winter and I have highlighted the difference between what we called "appreciative" and "formal" theory, with the former mostly expressed verbally, and much closer to the empirical details of the subject matter than the latter, and the latter articulated more abstractly, often in the form of a mathematical model, and more 
amenable to logical exploration and manipulation. While current use of the term "theory" in economics has tended to identify with formal theory, we argued that in economics most of the empirical research and interpretation of empirical phenomena, was structured by appreciative theory.

Modern economists tend to be pragmatic and flexible when they are doing empirical research, and engaging in serious policy discussion, or at least the best of them are. Does this mean that it really does not matter whether the theory articulated and taught, as formal theory, is neoclassical or evolutionary? I think it does matter. In the first place, while empirically oriented economists partially can escape the grip of neoclassical theory in the research and analysis they do, holding that theory still makes it difficult to appreciate the nature and role of innovation in economic activity, as various attempts to force innovation into a maximizing framework attest. It makes it difficult to recognize adequately that analyzing the behavior and performance of economic actors in a hypothetical equilibrium is not a good way to understand what is going on in contexts that clearly are out of equilibrium and in flux. In contrast, the perspective of modern evolutionary theory provides a framework that is helpful in analysis of economic dynamics.

Second, the theory one holds influences the empirical literature with which one is familiar. Scholars who hold strongly to neoclassical theory qua theory tend not to know about the extensive empirical literature on economic dynamics that has been the work of evolutionary economists, and which is published in journals and other outlets that draw in articles by economists who do not adhere to neoclassical theory. I am struck, for example, that my neoclassical colleagues who write about technological advance as the driving force behind economic growth tend not to be aware of Research Policy or Industrial and Corporate Change or The Journal of Evolutionary Economics where, in my view, much of the most interesting 
empirical work on firm and industry dynamics is being published.

Winter and I also argued that an important condition for progress in understanding empirical phenomena was that appreciative theorizing be able to draw on formal theory, which in turn required that formal theory be in tune with appreciative theory regarding the basic economic processes and contexts involved. In my discussion towards the start of this essay, I proposed that, in fact, in much of empirical research in economics, the researcher does not draw from, or even stick with, the canons of formal neoclassical theory. Rather there is recognition, explicit or implicit, that economic actors often are not in a position to "maximize" in any meaningful sense of that term, generally because the situation is in flux, and the best action highly uncertain, in the sense of Frank Knight and Joseph Schumpeter. The case for evolutionary economic theory is that it would be better if that recognition were explicit.

Economic development obviously involves change in an essential way; that is what the process is all about. It involves economic actors taking actions that break from previous behaviors, and an environment in continuing flux because of the innovating that is going on. Neoclassical theory has nothing to say about these kinds of conditions. On the other hand, they are exactly the conditions assumed in an evolutionary theory. For that reason, I believe that progress in understanding the processes of economic catch-up has to proceed under the implicit or explicit guidance of an evolutionary economic theory. That progress will be easier and faster if that guidance is explicit. 
References

Chandler, A, 1962, Strategy and Structure, The MIT Press, Cambridge

Chandler, A, 1977, The Visible Hand, Harvard Un. Press, Cambridge

Dosi, G, Freeman, C, Nelson, R, Silverberg, G., and Soete, L, 1988, Technical Change and Economic Theory, Pinter Publishers, London

Freeman, C, and Perez, C, 1988, Structural Crises of Adjustment, Business Cycles, and Investment Behavior, in dosi et al

Friedman, M, 1953, The Methodology of Positive Economics, in Friedman, Essays in Positive Economics, Un. Chicago Press, Chicago

Kim, L, and Nelson, R., 2000, Technology, Learning, and Innovation, Cambridge Un. Press, Cambridge

Knight, F, 1921, Risk, Uncertainty, and Profit ,Houghton Mifflin, Boston

Lall, S., 2000, Technological Change and Industrialization in the Asian Newly Industrializing Economies, in Kim and Nelson

Mazzoleni, R., and Nelson, R, forthcoming, The Roles of Research at Universities and Public Labs in Economic Catch-up, Research Policy

Murmann, P, 2003, Knowledge and Competitive Advantage, Cambridge Un. Press, Cambridge

Nelson, R, and Winter, S, 1982, An Evolutionary Theory of Economic Change, Harvard Un. Press, Cambridge

Nelson, R, and Pack, H, 1999, The Asian Miracle and Modern Growth Theory, Economic Journal, 109, pp 416-436

Simon, H, 1955, A Behavioral Model of Rational Choice, Quarterly Journal of Economics, 69, pp 99-118

Schumpeter, J, 1934, The Theory of Economic Development, Harvard Un. Press, Cambridge

Schumpeter, J, 1939, Business Cycles, McMillan, New York

Schumpeter, J., 1950, Capitalism, Socialism, and DemocracyHarper, New York 